\title{
Influence of Medium and Temperature on the Hydrolysis Kinetics of Propacetamol Hydrochloride: Determination Using Derivative Spectrophotometry
}

\author{
Emilia Barcia, ${ }^{*, a}$ Alicia Martin, ${ }^{a} \mathrm{M}^{\mathrm{a}}$ Luz Azuara, ${ }^{b}$ and Sofia Negro ${ }^{a}$ \\ ${ }^{a}$ Department of Pharmaceutics, University Complutense of Madrid, School of Pharmacy; 28040 Madrid, Spain: and \\ ${ }^{b}$ Palliative Care Unit, Spanish Cancer Association, "La Paz” Hospital; Madrid, Spain. \\ Received July 27, 2004; accepted November 2, 2004
}

\begin{abstract}
Propacetamol hydrochloride (PRO) is a water-soluble prodrug of paracetamol (PA) which can be parenterally administered as analgesic for the treatment of postoperative pain, acute trauma, and gastric and/or intestinal disorders where oral administration is not possible. In these circumstances, PRO can be administered in physiologic or glucose solutions since it is rapidly and quantitatively hydrolyzed into PA by plasma estearases. We have studied the degradation kinetics of PRO in $5 \%$ glucose and $0.9 \%$ saline solutions at $4{ }^{\circ} \mathrm{C}$ and $25^{\circ} \mathrm{C}$ (storage and room temperatures, respectively). The analytic technique used to determine PRO and PA quantitatively was first-derivative spectrophotometry. The degradation process of PRO can be best fitted to a secondorder kinetics with independence of the medium used (saline or glucose solution). The hydrolysis kinetics of PRO conversion into PA depends on the temperature but not on the assay medium (saline or glucose solution). The degradation rate constants obtained for PRO were approximately 4.5 times higher at $25^{\circ} \mathrm{C}$ than at $4{ }^{\circ} \mathrm{C}$. The values of $t_{90 \%}$ for PRO were $3.17 \mathrm{~h}$ and $3.61 \mathrm{~h}$ at $25^{\circ} \mathrm{C}$, and $13.42 \mathrm{~h}$ and $12.36 \mathrm{~h}$ at $4{ }^{\circ} \mathrm{C}$ when the tests were performed in $5 \%$ glucose and $0.9 \%$ saline solutions, respectively.
\end{abstract}

Key words propacetamol; paracetamol; first-derivative spectrophotometry; degradation kinetics

Paracetamol (acetaminophen; PA) is a poorly water-soluble analgesic that is widely used in hospital and ambulatory practice for the relief of mild to moderate pain associated with headache, backache, arthritis pain, and postoperative pain. ${ }^{1-3)}$ It has been used in the treatment of pain in combination with aspirin, caffeine, opiates and/or other agents. Paracetamol also has antipyretic effects that do not differ significantly from those of aspirin, although it has only weak antiinflammatory effects. ${ }^{4,5)}$

Paracetamol is a step 1 agent in the analgesic ladder of WHO ${ }^{6)}$ During the advanced stages of cancer, nearly $75 \%$ of the patients have pain that is moderate or severe, and according to the WHO analgesic ladder, the first step is used for the treatment of mild to moderate pain starting with either NSAIDs or PA.

In recommended therapeutic dosage regimens, PA is usually well tolerated. The most common side effect is lightheadedness. Skin rash and other allergic reactions occur occasionally. Overdoses of PA may cause nausea, vomiting, sweating, and exhaustion. The most serious adverse effect of acute overdosage is a dose-dependent, potentially fatal hepatic necrosis. ${ }^{7}$ )

Due to its poor water solubility that prevents parenteral administration in a soluble form, the clinical indications for PA are limited, especially in the postoperative setting. Contrary to the latter, propacetamol hydrochloride [ $N$ - $N$-diethyl, 4-acetylamino) phenyl ester monohydrochloride] (PRO) is a water-soluble prodrug of paracetamol, which can be parenterally administered as analgesic ${ }^{8,9)}$ for the treatment of postoperative pain, acute trauma, and gastric and/or intestinal disorders where oral administration is not possible. PRO has also shown efficacy in the symptomatic control of fever in the fields of oncology, infectious disease, and hematology. ${ }^{10-13)}$

In these circumstances, PRO can be administered in physi- ologic or glucose solutions since it is rapidly and quantitatively hydrolyzed into PA by plasma estearases within $7 \mathrm{~min}$ after intravenous injection. $\left.{ }^{8}\right)$ With the exception of absorption, PRO exhibits similar disposition kinetics when given by either the intravenous route as PA or by mouth as conventional tablets. ${ }^{14)}$

Screening of the literature revealed that PRO can be analytically determined by first-derivative spectrophotometry. ${ }^{15}$ ) This technique has been utilized to investigate the kinetics of drug degradation processes since it is an analytic tool that offers a convenient solution to a number of problems, especially its potential for increasing the detection sensitivity of minor spectral features. ${ }^{15-17)}$ The first-derivative spectrophotometric technique has the advantages of the speed, low cost, and environmental protection. The derivative methods circumvent the problem of overlapping spectral bands, allowing for the simultaneous determination of PRO and PA without prior separation, and providing accurate, precise, rapid, reproducible results. Therefore this was the analytic technique chosen for the present study.

Since PRO is frequently used as an intravenously administered analgesic we considered it interesting to determine the degradation kinetics of PRO in 5\% glucose and $0.9 \%$ saline solutions at $4{ }^{\circ} \mathrm{C}$ and $25^{\circ} \mathrm{C}$ (storage and room temperatures, respectively).

\section{Experimental}

Materials Pro-efferalgan vials were purchased from Upsa Medica Lab., Spain (batch 2E61952. The vials contain $2.00 \mathrm{~g}$ of PRO hydrochloride.

PA powder was purchased from Guinama S.A., Spain (batch 018). Physiologic solutions of $0.9 \%$ sodium chloride or $5 \%$ glucose were purchased from Grifols, Spain. Absolute ethanol for analysis was purchased from Merck (Germany).

Methods. Instrumentation A double-beam Beckman DU-7 UV-visible spectrophotometer connected to a computer was used. Previous tests were carried out to determine operating conditions. For example, different scanning speeds were tried out ranging from 60 to $120 \mathrm{~nm} \mathrm{~min}^{-1}$. The best 
results were obtained for a scanning speed of $60 \mathrm{~nm} \min ^{-1}$. The spectral bandwidth was $2 \mathrm{~nm}$.

The absorbance spectra of the test and reference solutions were recorded in 1-cm quartz cells over the range of $225-270 \mathrm{~nm}$. The main instrumental parameter affecting the shape of derivative spectra is $\Delta \lambda$. This parameter needs to be optimized to provide a good sensitivity and an adequate signalto-noise ratio. Various values of $\Delta \lambda$ were tested and a value of $\Delta \lambda=8 \mathrm{~nm}$ was found optimal in connection with both slit width and wavelength interval. Under these conditions, smoothing function was not necessary. Apart from this, no specific expedients were found necessary to optimize the procedure.

A digital Crison GLP-22 pH-meter was used to determine the $\mathrm{pH}$ of all the solutions assayed, since this parameter could play a major role in the prevalence of local skin irritation. ${ }^{18,19)}$

Standard Solutions The analytic technique used to determine quantitatively PRO and PA in the tests solutions was the first-derivative spectrophotometry. The method used was that proposed by Ródenas et al., ${ }^{17)}$ slightly modified by us to measure the amplitudes (nm) at $248.7 \mathrm{~nm}$ for PRO and $245.7 \mathrm{~nm}$ for PA.

Method validation was performed according to the Proceedings of the International Conference on Harmonization $(\mathrm{ICH}) .{ }^{20)}$ Validations were run on three consecutive days and included calibration curves processed in triplicate for each drug. The standard stock solutions of PRO $(1 \mathrm{mg} / \mathrm{ml})$ and PA $(1 \mathrm{mg} / \mathrm{ml})$ were prepared by dissolving $25 \mathrm{mg}$ of PRO or PA in $25 \mathrm{ml}$ of absolute ethanol. Different volumes of the standard stock solutions of PRO and PA were diluted with ethanol to give a final concentration ranging from $2.5-20 \mathrm{mg} / 1$ for PRO and from $2.5-15 \mathrm{mg} / 1$ for PA. Calibration curves for both PRO and PA were linear over the range examined and coefficients of determination $\left(r^{2}\right)$ were consistently greater than 0.999 . The detection limits achieved for PRO and PA were 0.41 and $0.25 \mathrm{mg} / 1$, respectively.

To investigate the effects of PRO and PA on their simultaneous determination, calibration curves for each drug were obtained with samples at a constant concentration of one of the components and variable concentrations of the other. The concentrations tested were $2.5,10$, and $20 \mathrm{mg} / 1$ for PRO with a constant of $15 \mathrm{mg} / 1$ for PA or, in the other case, $2.5,10$ and $15 \mathrm{mg} / 1$ for PA with a constant concentration of $20 \mathrm{mg} / \mathrm{l}$ for PA. The results were not altered by the simultaneous presence of PA and PRO.

Between- and within-assay reproducibility was assessed by quantifying six replicates of three standard samples on 3 consecutive days. The concentrations of PRO used were 2.5, 10, and $17.5 \mathrm{mg} / 1$ and those of PA were 2.5, 7.5 , and $12.5 \mathrm{mg} / \mathrm{l}$. When analyzed using two-way analysis of variance, the within-assay coefficient of variation (CV) was $1.7 \%$ for PA and $1.88 \%$ for PRO, and the between-assay CV was $2.3 \%$ for PA and $3.5 \%$ for PRO.

Stability Studies The study of the degradation kinetics of PRO was performed at $4{ }^{\circ} \mathrm{C}$ and $25^{\circ} \mathrm{C}$ in $0.9 \%$ saline and $5 \%$ glucose solutions. The tests solutions were prepared by dissolving $250 \mathrm{mg}$ of PRO (obtained from Proefferalgan vials) in $25 \mathrm{ml}$ of $0.9 \%$ saline or $5 \%$ glucose sterilized physiologic solutions. Different aliquots of the previous solutions were kept at $4{ }^{\circ} \mathrm{C}$ (refrigerator) and $25^{\circ} \mathrm{C}$ (stability oven) for $132 \mathrm{~h}$ and $60 \mathrm{~h}$, respectively, with independence of the medium used in each case. At preestablished times, the samples were diluted with absolute ethanol. The first-order derivative spectrum of these solutions was recorded under the same instrumental conditions described above. Each sample was prepared and tested six times.

Analysis of Kinetic Data The in vitro degradation kinetics of PRO at both temperatures and media assayed was studied after fitting the experimental data obtained to zero-, one-, and second-order kinetics. The Statgraphics Plus 4.0 (John Wiley and Sons, New York) computer program was utilized to estimate the values of the rate degradation constants.

Before pooling the data from several batches to estimate $t_{90 \%}$, a preliminary statistical study was performed to determine whether the regression lines from different batches had a common slope and a common time-zero intercept. Analysis of covariance (ANCOVA) was used, where time is considered the covariate, to determine the differences in slopes and intercepts of the regression lines among batches. Although the $\mathrm{ICH}^{21)}$ uses a significance level of 0.25 to compensate for the expected low power of the design due to the relatively limited sample size in a typical formal stability study, in our case, since we used six batches, the significance level used was 0.05. The Statgraphics Plus 4.0 computer program was used for this statistical analysis. If the tests for equality of slopes and equality of intercepts do not result in rejection at the significance level of 0.05 (i.e., there is no significant difference in slope and intercepts among batches), the data from all batches can be combined.

\section{Results and Discussion}

PRO is administered intravenously after surgery to patients who are unable to take oral medication. A commercial vial of PRO reconstituted immediately before use can be intravenously administered in $5 \%$ glucose or $0.9 \%$ saline solution. In vivo and in vitro studies have shown that PRO is quickly and quantitatively hydrolyzed into PA: $1 \mathrm{~g}$ of PRO generates $500 \mathrm{mg}$ of PA.

The stability of PRO in reconstituted solutions dissolved in $100 \mathrm{ml}$ of either $5 \%$ glucose or $0.9 \%$ saline solution at $4{ }^{\circ} \mathrm{C}$ and $25^{\circ} \mathrm{C}$ was studied following the experimental procedures previously described. The $\mathrm{pH}$ values at the beginning of the tests were 3.85 and 3.70 for saline and glucose solutions, respectively. During the stability study a decrease in the $\mathrm{pH}$ values was observed, with final $\mathrm{pH}$ values of approximately 2, for all the solutions and temperatures assayed. Tables 1 and 2 show the mean values of the kinetic rate constants calculated for PRO and PA in both media and estimated after fitting to zero-, first-, and second-order kinetics the experimental data obtained when performing the stability tests at $25^{\circ} \mathrm{C}$ and $4^{\circ} \mathrm{C}$, respectively. The tables also include the correlation coefficients (calculated from the mean values) as well as the ranges of the rate constants obtained in each individual test.

Tests Performed in 5\% Glucose Solution The average loss of PRO after $60 \mathrm{~h}$ (final sampling time at $25^{\circ} \mathrm{C}$ ) was approximately $64 \%$ when the stability studies were performed at $25^{\circ} \mathrm{C}$. At that time, the percentage was much lower, approximately $28 \%$, when the tests were carried out at $4{ }^{\circ} \mathrm{C}$. After fitting to zero-, first-, and second-order kinetics the experimental data obtained for PRO in the stability tests performed at $25^{\circ} \mathrm{C}$ and $4{ }^{\circ} \mathrm{C}$, the best results were obtained when data were fitted to second-order kinetics (Fig. 1).

The six replicates prepared for each sample were statistically equal after ANCOVA analysis, that is, the regression lines from the different batches had a common slope and a common time-zero intercept $(\alpha=0.05)$. Therefore all the experimental data obtained from all the batches were combined to estimate the mean values. In this case, the mean values and ranges of the degradation rate constants were $2.77 \times 10^{-3} \mathrm{ml} / \mathrm{mg} \cdot \mathrm{h}\left(2.67 \times 10^{-3}-2.96 \times 10^{-3} \mathrm{ml} / \mathrm{mg} \cdot \mathrm{h}\right)$ at $25^{\circ} \mathrm{C}$ and $6.1 \times 10^{-4} \mathrm{ml} / \mathrm{mg} \cdot \mathrm{h}\left(5.33 \times 10^{-4}-6.78 \times 10^{-4} \mathrm{ml} /\right.$ $\mathrm{mg} \cdot \mathrm{h})$ at $4{ }^{\circ} \mathrm{C}$ (Tables 1,2$)$.

The values of $t_{90 \%}$ for PRO (the time it takes for the substance to degrade by $10 \%$ ) were $3.17 \mathrm{~h}$ at $25^{\circ} \mathrm{C}$ and $13.42 \mathrm{~h}$ at $4{ }^{\circ} \mathrm{C}$, and the six batches were statistically equal. At these times, the reduction obtained for the $\mathrm{pH}$ values of the solutions was of approximately $1 \mathrm{pH}$ unit, which is worth considering because the $\mathrm{pH}$ of the solution is important in local intolerance to parenteral administration. Despite the low $\mathrm{pH}$ of the solutions, Depré et al. ${ }^{8)}$ reported that the local and systemic tolerability of $1 \mathrm{~g}$ and $2 \mathrm{~g}$ of PRO given intravenously was excellent.

The experimental data obtained for PA were fitted to zero-, first-, and second-order kinetics with the best fit obtained with zero-order kinetics (Fig. 2) if goodness of fit is used as a selecting factor for the reaction kinetics.

The ANCOVA $(\alpha=0.05)$ performed showed that there was no significant difference in slope and intercept among the batches which permitted combining all the experimental data. In this case, the mean values and ranges of the appear- 


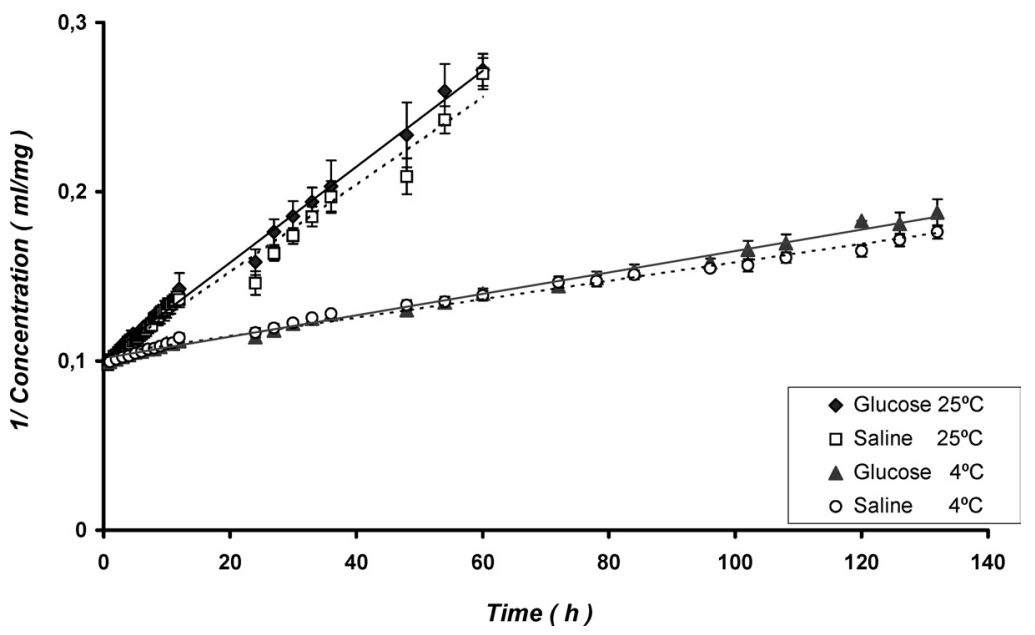

Fig. 1. Mean Profiles ( \pm S.D.) Obtained after Fitting to Second-Order Kinetics the Experimental Data Obtained for PRO

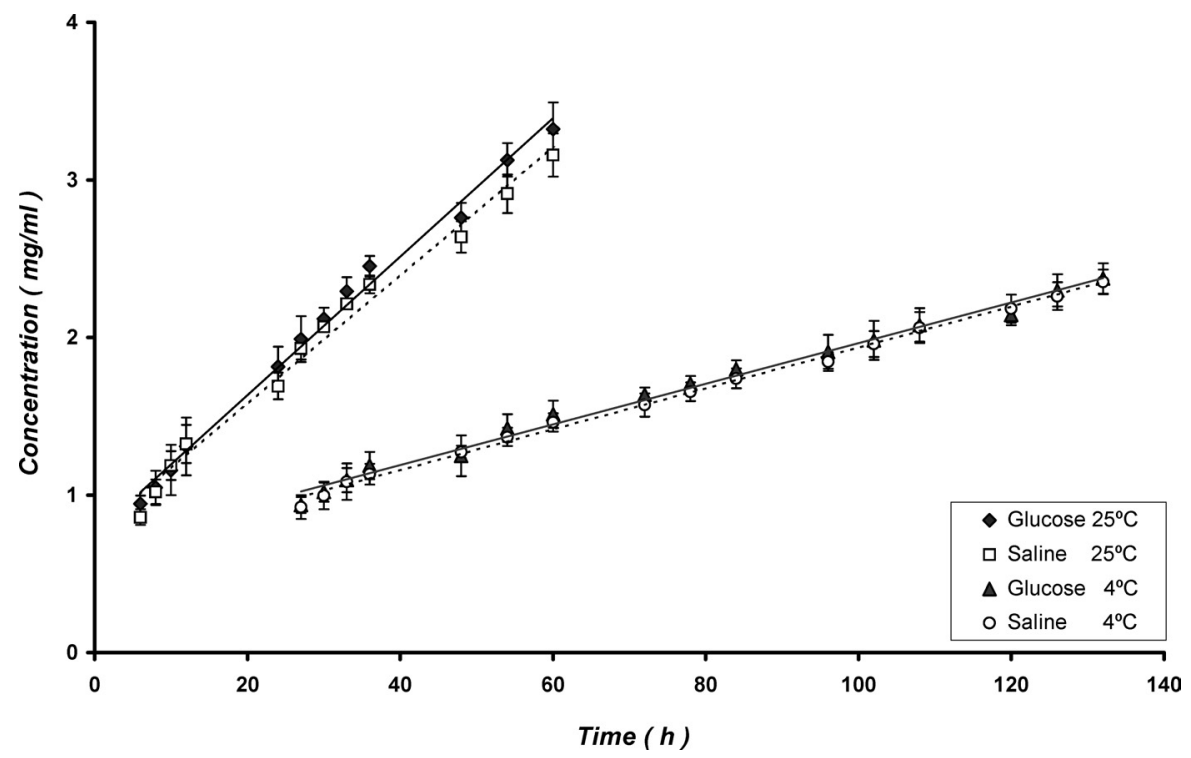

Fig. 2. Mean Profiles ( \pm S.D.) Obtained after Fitting to Zero-Order Kinetics the Experimental Data Obtained for PA

ance rate constants were $4.45 \times 10^{-2} \mathrm{mg} / \mathrm{ml} \cdot \mathrm{h}\left(3.92 \times 10^{-2}\right.$ $\left.5.15 \times 10^{-2} \mathrm{mg} / \mathrm{ml} \cdot \mathrm{h}\right)$ at $25^{\circ} \mathrm{C}$ and $1.29 \times 10^{-2} \mathrm{mg} / \mathrm{ml} \cdot \mathrm{h}$ $\left(1.13 \times 10^{-2}-1.46 \times 10^{-2} \mathrm{mg} / \mathrm{ml} \cdot \mathrm{h}\right)$ at $4{ }^{\circ} \mathrm{C}$ (Tables 1,2$)$.

PRO hydrolyzes as previously indicated in a second-order kinetic process and PA is the only degradation product found for PRO. Therefore both reaction mechanisms should be the same. However, the use of the goodness of fit for the selection of the reaction model can be problematic in some cases. Moreover, in our case, the differences found in the $r$ values between second-order and zero-order models are probably not sufficiently large to assume strongly that PA exhibits a different reaction than $\mathrm{PRO}$.

It should also be pointed out that the differences found between observed and estimated values for PA correspond to the first experimental data, which are close to the quantification limit in both fitting models (second- and zero-order reactions).

The free PA content increased with time as PRO hydrolyzed, and the PA released at every sampling time was in accordance with the quantity of PRO hydrolyzed. After $60 \mathrm{~h}$ of the stability test, a PA recovery of approximately $64 \%$ (percentage of recovery corresponding to the maximum possible) at $25^{\circ} \mathrm{C}$ was obtained whereas a percentage of $31 \%$ was recovered when the tests were realized at $4{ }^{\circ} \mathrm{C}$.

Tests Performed in $\mathbf{0 . 9 \%}$ Saline Solution The average loss of PRO after $60 \mathrm{~h}$ was approximately $64 \%$ when the tests were performed at $25^{\circ} \mathrm{C}$. This percentage was much lower, approximately $29 \%$, when the tests were carried out at $4{ }^{\circ} \mathrm{C}$. These values did not differ significantly from the results obtained in 5\% glucose solution.

After fitting the experimental data to zero-, first-, and second-order kinetics obtained for PRO in the tests performed at $25^{\circ} \mathrm{C}$ and $4{ }^{\circ} \mathrm{C}$, the best results were obtained when data were fitted to second-order kinetics (Fig. 1). In this case, the mean values and ranges of the degradation rate constant were $2.60 \times 10^{-3} \mathrm{ml} / \mathrm{mg} \cdot \mathrm{h}\left(2.34 \times 10^{-3}-2.77 \times 10^{-3} \mathrm{ml} / \mathrm{mg} \cdot \mathrm{h}\right)$ at $25^{\circ} \mathrm{C}$ and $5.47 \times 10^{-4} \mathrm{ml} / \mathrm{mg} \cdot \mathrm{h} \quad\left(5.12 \times 10^{-4}-5.64 \times 10^{-4}\right.$ $\mathrm{ml} / \mathrm{mg} \cdot \mathrm{h}$ ) at $4{ }^{\circ} \mathrm{C}$ (Tables 1,2$)$. The $t_{90 \%}$ values for PRO (all six batches were statistically equal) were $3.61 \mathrm{~h}$ and $12.36 \mathrm{~h}$ at $25^{\circ} \mathrm{C}$ and $4{ }^{\circ} \mathrm{C}$, respectively.

The experimental data obtained for PA were fitted to zero-, first-, and second-order kinetics with the best fit obtained to 
Table 1. Mean Values and Ranges of the Kinetic Rate Constants Calculated for PRO and PA at $25^{\circ} \mathrm{C}$

\begin{tabular}{|c|c|c|c|c|c|}
\hline & & \multicolumn{2}{|c|}{ Propacetamol } & \multicolumn{2}{|c|}{ Paracetamol } \\
\hline & & Glucose solution & Saline solution & Glucose solution & Saline solution \\
\hline $\begin{array}{c}K \text { (zero-order) } \\
(\mathrm{mg} / \mathrm{ml} \cdot \mathrm{h})\end{array}$ & $\begin{array}{c}K\left(\times 10^{2}\right) \\
r\end{array}$ & $\begin{array}{c}10.54 \\
{[9.90-11.16]} \\
-0.966\end{array}$ & $\begin{array}{c}10.53 \\
{[9.94-11.02]} \\
-0.952\end{array}$ & $\begin{array}{c}4.45 \\
{[3.92-5.15]} \\
0.991\end{array}$ & $\begin{array}{c}4.01 \\
{[3.67-4.41]} \\
0.991\end{array}$ \\
\hline $\begin{array}{c}K \text { (first-order) } \\
\left(\mathrm{h}^{-1}\right)\end{array}$ & $\begin{array}{c}K\left(\times 10^{2}\right) \\
r\end{array}$ & $\begin{array}{c}1.64 \\
{[1.58-1.76]} \\
-0.987\end{array}$ & $\begin{array}{c}1.61 \\
{[1.49-1.69]} \\
-0.981\end{array}$ & $\begin{array}{c}2.18 \\
{[1.78-2.64]} \\
0.962\end{array}$ & $\begin{array}{c}2.11 \\
{[1.92-2.27]} \\
0.963\end{array}$ \\
\hline $\begin{array}{c}K \text { (second-order) } \\
(\mathrm{ml} / \mathrm{mg} \cdot \mathrm{h})\end{array}$ & $\begin{array}{c}K\left(\times 10^{3}\right) \\
r\end{array}$ & $\begin{array}{c}2.77 \\
{[2.67-2.96]} \\
0.989\end{array}$ & $\begin{array}{c}2.60 \\
{[2.34-2.77]} \\
0.989\end{array}$ & $\begin{array}{c}13.08 \\
{[15.32-11.40]} \\
-0.907\end{array}$ & $\begin{array}{c}12.24 \\
{[10.93-13.67]} \\
-0.910\end{array}$ \\
\hline
\end{tabular}

Table 2. Mean Values and Ranges of the Kinetic Rate Constants Calculated for PRO and PA at $4{ }^{\circ} \mathrm{C}$

\begin{tabular}{|c|c|c|c|c|c|}
\hline & & \multicolumn{2}{|c|}{ Propacetamol } & \multicolumn{2}{|c|}{ Paracetamol } \\
\hline & & Glucose solution & Saline solution & Glucose solution & Saline solution \\
\hline $\begin{array}{c}K \text { (zero-order) } \\
(\mathrm{mg} / \mathrm{ml} \cdot \mathrm{h})\end{array}$ & $\begin{array}{c}K\left(\times 10^{2}\right) \\
r\end{array}$ & $\begin{array}{c}3.46 \\
{[3.07-3.70]} \\
-0.982\end{array}$ & $\begin{array}{c}3.14 \\
{[3.06-3.22]} \\
-0.972\end{array}$ & $\begin{array}{c}1.29 \\
{[1.13-1.46]} \\
0.994\end{array}$ & $\begin{array}{c}1.30 \\
{[1.09-1.45]} \\
0.995\end{array}$ \\
\hline $\begin{array}{c}K \text { (first-order) } \\
\left(\mathrm{h}^{-1}\right)\end{array}$ & $\begin{array}{c}K\left(\times 10^{3}\right) \\
r\end{array}$ & $\begin{array}{c}2.00 \\
{[1.74-2.15]} \\
-0.992\end{array}$ & $\begin{array}{c}1.78 \\
{[1.70-1.82]} \\
-0.985\end{array}$ & $\begin{array}{c}3.57 \\
{[3.07-3.91]} \\
0.979\end{array}$ & $\begin{array}{c}8.72 \\
{[6.72-11.50]} \\
0.977\end{array}$ \\
\hline $\begin{array}{c}K \text { (second-order) } \\
(\mathrm{ml} / \mathrm{mg} \cdot \mathrm{h})\end{array}$ & $\begin{array}{c}K\left(\times 10^{4}\right) \\
r\end{array}$ & $\begin{array}{c}6.12 \\
{[5.33-6.78]} \\
0.995\end{array}$ & $\begin{array}{c}5.47 \\
{[5.12-5.64]} \\
0.993\end{array}$ & $\begin{array}{c}5.49 \\
{[4.60-6.47]} \\
-0.948\end{array}$ & $\begin{array}{c}6.40 \\
{[4.26-10.87]} \\
-0.930\end{array}$ \\
\hline
\end{tabular}

zero-order kinetics (Fig. 2). In this case, the mean values and ranges of the appearance rate constant were $4.01 \times 10^{-2}$ $\mathrm{mg} / \mathrm{ml} \cdot \mathrm{h}\left(3.67 \times 10^{-2}-4.41 \times 10^{-2} \mathrm{mg} / \mathrm{ml} \cdot \mathrm{h}\right)$ at $25^{\circ} \mathrm{C}$ and $1.30 \times 10^{-2} \mathrm{mg} / \mathrm{ml} \cdot \mathrm{h}\left(1.09 \times 10^{-2}-1.45 \times 10^{-2} \mathrm{mg} / \mathrm{ml} \cdot \mathrm{h}\right)$ at $4{ }^{\circ} \mathrm{C}$ (Tables 1,2$)$. The same comments apply as indicated for the tests performed in 5\% glucose.

After $60 \mathrm{~h}$ of the stability test, approximately $64 \%$ of PA was recovered at $25^{\circ} \mathrm{C}$ (percentage of recovery corresponding to the maximum possible), whereas $29 \%$ was recovered when the tests were performed at $4{ }^{\circ} \mathrm{C}$.

When comparing the results obtained in both media $(5 \%$ glucose and $0.9 \%$ saline solutions), it was found that the hydrolysis kinetics of PRO conversion into PA does not depend on the medium. These results are not in accordance with the ones published by Ródenas et al. ${ }^{17)}$ that reported a negligible hydrolysis of PRO in saline solution after $3 \mathrm{~h}$ and a $75.4 \%$ degradation in $5 \%$ glucose solution after $80 \mathrm{~min}$ of initiating the stability test. It should be noted that the authors of the latter paper did not take into consideration the influence that temperature has on the stability of PRO, which we have pointed out in our work.

\section{Conciusions}

The degradation process of PRO can be best fitted to second-order kinetics independent of the medium used (saline or glucose solution). The hydrolysis kinetics of PRO conversion into PA depends on the temperature but not on the assay medium (saline or glucose solution). The degradation rate constants obtained for PRO were approximately 4.5 times higher at $25^{\circ} \mathrm{C}$ than at $4{ }^{\circ} \mathrm{C}$. The values of $t_{90 \%}$ for PRO were $3.17 \mathrm{~h}$ and $3.61 \mathrm{~h}$ at $25^{\circ} \mathrm{C}$, and $13.42 \mathrm{~h}$ and $12.36 \mathrm{~h}$ at $4{ }^{\circ} \mathrm{C}$ when the tests were performed in $5 \%$ glucose and $0.9 \%$ saline solutions, respectively.

\section{References}

1) Farhat F., Savoyen M. C., Jayr C., Cahiers d'LAnesthesiologie, 43, 351-356 (1995).

2) Beaulieu P., Anesthesia, 49, 739-740 (1994).

3) Pettersson H., Owall A., Jakobsson J., Acta Anaesthesiol. Scand., 48 , $867-870$ (2004)

4) “Martindale 31 ed." E.F. Reynolds, London, 1996, pp. 81-85.

5) "Goodman and Gilman's: The Pharmacological Basis of Therapeutics," 10 th ed., McGrawHill, New York, 2001, pp. 624-663.

6) Care pain relief and palliative care. Technical Report Series 804, WHO, 1990.

7) Forrest J. A. H., Clements J. A., Prescott L. F., Clin. Pharmacokinet., 7, 93-107 (1982).

8) Depré M., Van Hecken A., Verbesselt R., Tjandra-Maga T. B., Gerin M., Schepper P. J., Fund. Clin. Pharmacol., 6, 259-262 (1992).

9) Flouvat B., Leveneu A., Fitoussi S., Delhotal-Landes B., Gendron A., Int. J. Clin. Pharmacol. Ther, 42, 505-507 (2004).

10) Oborilova A., Mayer J., Pospisil Z., Koristek Z., J. Pain Symptom Manage., 24, 608-615 (2002).

11) Granry J. C., Paediatr. Anaesth., 7, 445-449 (1997).

12) White P. F., Anesth. Analg., 92, 1569-1575 (2001).

13) Peduto V. A., Anaesthesiol. Scand., 42, 293-298 (1998).

14) Bannwarth B., Netter P., Lapicque F., Gillet P., Pere P., Boccard E., Royer R. J., Gaucher A., Br. J. Clin. Pharmacol., 34, 79-81 (1992).

15) Hassan E. M., J. Pharm. Biomed. Anal., 21, 1183-1189 (2000).

16) Morelli B., J. Pharm. Biomed. Anal., 33, 423- 433 (2003).

17) Ródenas V., García M. S., Sánchez-Pedreño C., Albero M. I., Talanta, 52, 517-523 (2000).

18) Lewis G. B. H., Hecker J. F., Br. J. Anaesth., 57, 220-233 (1985).

19) Fransson J., Espander-Jansson A., J. Pharm. Pharmacol., 48, 10121015 (1996).

20) International Conference on Harmonization (ICH). "Validation of Analytical Procedures: Methodology,” ICH Q2B, 1996.

21) International Conference on Harmonization (ICH). "Evaluation of Statistical Data," ICH Q1E, 2002. 